\title{
Trapos que aconchegam: o envelhecimento feminino em Lygia Fagundes Telles
}

\author{
Rags that comfort: \\ feminine aging in Lygia Fagundes Telles \\ Trapos que acogen: \\ el envejecimiento femenino en Lygia Fagundes Telles \\ Márcia Regina Schwertner ${ }^{*}$ \\ Roseli Bodnar
}

\section{Resumo}

Lygia Fagundes Telles publicou As horas nuas no ano de 1989, entregando-nos Rosa Ambrósio, uma personagem marcante que se confronta com o cotidiano da velhice após uma carreira profissional toda dedicada à arte. Atriz e intérprete da vida, Rosa Ambrósio, ao sair dos palcos, percebe-se sendo interpretada a partir de preconceitos alheios: o olhar que lhe dirigem agora vê nela o outro, a idosa, sobre a qual é comum ter uma opinião generalista e estereotipada ou sequer ter opinião, a indiferença poupando-nos do medo de ver. Personifica-se na figura de Rosa Ambrósio uma trajetória do palco para o esquecimento, do público para o privado. Observar o seu percurso permite vislumbrar a importância do exercício mediador da literatura para a conscientização do modo como lidamos com a velhice, em especial com o envelhecimento feminino. Nossa análise parte da seguinte questão: até que ponto os novos papeis hoje assumidos pelos idosos se opõem a estereótipos e preconceitos e em que medida revalidam em novos formatos posicionamentos perniciosos que há muito deveriam ter sido ultrapassados? Para a elaboração do artigo, foram pesquisados textos de Simone de Beauvoir, Ecléa Bosi e Robert Burtler, publicados nas décadas de 60 e 70, mas ainda hoje referências no estudo da velhice, e obras de publicação mais recente, como, entre outras, as de Guita Debert, António Fonseca, Miriam Goldenberg e Sibila Marques. Conclui-se que a visão negativa da velhice, se ainda fortemente enraizada, já se comprovou como equívoco e que estereótipos excludentes começam a ser substituídos por uma mudança gradativa de viés, resultante também da ampliação de pesquisas na área, que envolvem diferentes setores, métodos e linhas de pensamento, enfatizando a variedade e inconclusividade de definições sobre o tema.

Palavras-chave: Lygia Fagundes Telles, As horas nuas, velhice, literatura.

\begin{abstract}
Lygia Fagundes Telles published As horas nuas (Naked Hours) in 1989, introducing Rosa Ambrósio, an outstanding character who faces the daily life of old age after a career dedicated to art. An actress and an interpreter of life, Rosa Ambrósio, after leaving the stage, feels herself being interpreted from the perspective of other people's prejudices: the look they direct towards her now sees the other in her, the elderly woman, about whom it is common to have a generalized and stereotyped opinion or to have no opinion at all, an indifference that spares the reader the fear of looking. The figure of Rosa Ambrósio personifies a trajectory from the stage to oblivion, from public to private. Observing her journey allows for a glimpse at the importance
\end{abstract}

\section{Resumen}

Lygia Fagundes Telles publicó As horas nuas (Las horas desnudas) en el año 1989, entregándonos a Rosa Ambrósio, personaje que se enfrenta con el cotidiano de la vejez tras una trayectoria profesional completamente dedicada al arte. Actriz e intérprete de la vida, Rosa Ambrósio, al salir de los escenarios, se percibe siendo interpretada a partir de prejuicios ajenos: la mirada que le dirigen ahora ve en ella al otro, a la anciana, sobre la cual es común tener una opinión generalista y estereotipada o incluso ni siquiera tener opinión, la indiferencia ahorrándonos del miedo de ver. Se personifica en la figura de Rosa Ambrósio una trayectoria del escenario para el olvido, de lo público a lo privado. Observar su recorrido permite vislumbrar la importancia del

\footnotetext{
* Doutoranda em estudos literários, culturais e interartísticos pela Universidade do Porto (UP), Porto, Portugal. (Dorcid.org/00000002-0796-422X. E-mail: marcia454rs@gmail.com

** Doutora em letras e professora da Universidade Federal do Tocantins (UFT), Palmas, TO, Brasil. (Dorcid.org/0000-0002-84742196. E-mail: roseliteratura@hotmail.com
} 
of literature's mediating exercise to raise awareness about how we deal with old age, especially with female aging. Our analysis is based on the following questions: to what extent do the new roles now assumed by the elderly oppose stereotypes and prejudices, and to what extent do they revalidate, in new formats, pernicious positions that should have been overcome long ago? For the elaboration of this article, texts of Simone de Beauvoir, Ecléa Bosi and Robert Burtler were researched, which, although published in the 1960s and 1970s, are still references in the study of old age, as well as more recent publications such as those of Guita Debert, António Fonseca, Miriam Goldenberg and Sibila Marques, among others. It is concluded that the negative view of old age, if still strongly ingrained, has already proven to be a mistake, and that exclusionary stereotypes are beginning to be replaced by a gradual change of perspective, in part, a result of the expanding research in the area, involving different sectors, methods and approaches, and emphasizing the variety and inconclusiveness of definitions on the subject.

Keywords: Lygia Fagundes Telles, Naked hours (As horas nuas), old age, literature. ejercicio mediador de la literatura para la concientización de cómo lidiamos con la vejez, en especial con el envejecimiento femenino. Nuestro análisis parte de la siguiente pregunta: ¿hasta qué punto los nuevos papeles hoy asumidos por los ancianos se oponen a estereotipos y prejuicios y en qué medida revalidan en nuevos formatos posiciones perniciosas que hace mucho deberían haber sido superadas? Para la elaboración del artículo, fueron investigados textos de Simone de Beauvoir, Ecléa Bosi y Robert Burtler, publicados en las décadas del 60 y 70, pero aún hoy referencias en el estudio de la vejez, y obras de publicación más reciente, entre otras, las de Guita Debert, António Fonseca, Miriam Goldenberg y Sibila Marques. Se concluye que la visión negativa de la vejez aún si está fuertemente enraizada, ya se ha comprobado como equívoca y que los estereotipos excluyentes empiezan a ser sustituidos por un cambio gradual de perspectiva, resultante también de la ampliación de las investigaciones en el área, que engloban diferentes sectores, métodos y líneas de pensamiento, enfatizando la variedad e inconclusividad de las definiciones sobre el tema.

Palabras clave: Lygia Fagundes Telles, Las horas desnudas (As horas nuas), vejez, literatura.

"ô! meu Pai, tantas perdas"

Lygia Fagundes Telles, As horas nuas

Característica marcante da sociedade contemporânea, o envelhecimento demográfico trouxe consigo modos diferenciados de ver e perceber a realidade, ampliando, em especial na segunda metade do século XX, o olhar que destinamos ao idoso. Idoso, ancião, velho, velhice, terceira idade, senescência, senilidade, quarta idade, esses termos não são aleatórios, sua diversidade tem contato próximo com o aumento de pesquisas e reflete mudanças culturais significativas (Peixoto, 1998). Nominar é permitir ser, novas designações são construídas, assumindo-se que identidades - substantivo plural - compõem esse período. Outros enfoques, instrumentos e nuances são adotados, como destaca António Manuel Fonseca:

[...] ao longo da segunda metade do século foram emergindo concepções de natureza multidisciplinar que reflectiam conceitos diferenciados de desenvolvimento. Essas concepções baseiam-se no pressuposto de que o desenvolvimento ocorre ao longo de toda a vida e é determinado não apenas pela idade mas por múltiplos outros factores, o que acabou por alargar a própria esfera de aç̧ão da ciência desenvolvimental (Fonseca, 2004, p. 19).

Isso torna as pesquisas mais complexas, relativizando a questão cronológica. A heterogeneidade cresce em importância, distintas variáveis são consideradas e as experiências individuais ou, quando coletivas, as visões individuais sobre essas experiências mostram-se decisivas no processo de envelhecimento, influenciando a escolha de caminhos e os resultados em termos físicos e psicológicos que essas escolhas acarretam.

Publicado pela primeira vez no ano de 1989, ${ }^{1}$ As horas nuas, de Lygia Fagundes Telles, debruça-se sobre o cotidiano de uma atriz enfrentando o processo de exclusão profissional e

\footnotetext{
${ }^{1} \mathrm{O}$ ano de publicação da obra de Telles torna-se importante na abordagem aqui feita. Segundo Guita Debert (1999) e António Manuel Fonseca (2004), as décadas de 80 e 90 foram fundamentais para o processo de visibilidade do idoso, observado não apenas no universo brasileiro, mas como situação de ampla abrangência no contexto ocidental. No Brasil, são exemplificativos os
} 
social decorrente da idade. No livro, o tema do envelhecimento feminino aparece de forma quase protagonista, na medida em que direciona boa parte das ações e sentimentos vivenciados pela personagem Rosa Ambrósio: acostumada a interpretar a vida, ela percebese agora interpretada a partir do olhar alheio.

No universo artístico, condensam-se preconceitos e oportunidades, o que o torna um microcosmo social propício para a percepção do modo como lidamos com a velhice. A protagonista de Telles é atriz, uma "burguesa assumida", como se autodeclara, tem por volta de 60 anos e se confronta com preconceitos próprios e externos que limitam seus espaços de atuação. Longe dos palcos, vive em um apartamento de luxo, acompanhada da empregada, Dionísia, e de um gato, Rahul. Seu marido morreu, o amante a abandonou e a filha mantém-se não distanciada, mas também não muito presente.

Lygia Fagundes Telles é uma escritora ímpar. Juntamente com Clarice Lispector e Rachel de Queiroz, impulsionou a visibilidade feminina no contexto literário brasileiro, claramente masculino até meados do século XX, principalmente se pensarmos em termos de espaço junto à crítica jornalística ou acadêmica.

Não é a primeira vez que a autora trata do envelhecimento feminino, é um tema que já aparece em "Senhor Diretor", de 1977. Nesse conto, publicado em Seminário dos ratos, Maria Emília, uma professora aposentada, decide enviar uma carta ao diretor de um jornal popular, como protesto contra o que considera "a sufocante atmosfera de vulgaridade" (Telles, 1998, p. 17) presente na mídia. No planejamento que faz do texto que pretende redigir, Maria Emília percorre assuntos e associações que a levam a rever, a partir do presente, noções e valores que acreditava possuir. Posteriormente, em 1995, Telles publica A noite escura e mais eu, coletânea na qual dois contos se destacam pela forma como provocam no leitor a necessidade de um novo olhar sobre a velhice: "Papoulas em feltro negro" e "Boa noite, Maria".

A ênfase na fisicalidade caracteriza esses textos e é instrumento de quebra da memória formalmente construída pelas personagens. O encontro com o passado, que se consubstancia na presença física da figura humana, produz o estranhamento, em um exercício de busca de significados que permitam a conscientização necessária ao crescimento e à mudança.

Contudo, ainda que nesses contos personagens idosas estejam presentes e exerçam posição central na história, nos romances de Lygia Fagundes Telles o protagonismo é assumido majoritariamente por jovens em seu ingresso no mundo adulto, o que se altera na escrita de As horas nuas. Não obstante, se a opção pela abordagem do envelhecimento feminino modificou a faixa etária mais comumente encontrada nos romances da autora, observam-se em As horas nuas elementos, perspectivas, estruturas e conteúdos característicos de sua obra. As personagens são complexas, com fortes tons psicológicos, vivem trajetórias de busca de inserção em um mundo no qual coexistem com uma sensação de não pertencimento, suas procuras por sentido partem de perplexidades e indagações frente a um contexto que não reconhecem como seu.

Encontramos em As horas nuas um entrelaçamento de vozes que se dispersam na medida em que ampliam seus significados. Isso se complementa pela inexistência de uma clara delimitação espacial e temporal: o tempo e o espaço quebram-se na sobreposição de diferentes planos. Uma multiplicidade de dramas cotidianos se entrecruza, fragmentados em narrativas paralelas, nunca aleatórias, perpassadas por sensações, intertextualidades e tramas que se iluminam a si mesmas ao mesmo tempo em que provocam nebulosidades. Em comum, a incompletude, uma das marcas do processo de escrita de Telles.

Uma cena ou personagem não se completa no texto, mas em sua interpretação pelo leitor, exigindo deste um trabalho cúmplice de união de pontas dispersas, de encontro de chaves interpretativas. Mesmo após o término da leitura, a solaridade de Rosa Ambrósio nos

movimentos sociais dos anos 80, como as lutas pela reforma da Previdência e a elaboração da Constituição de 1988, que contaram com forte participação de aposentados, resultando em um processo de conscientização sobre as condições de vida excludentes e precárias a que não raro são submetidas as pessoas idosas. 
desconcerta e Ananta ainda nos intriga com sua obsessão pelo "Vizinho que chegava todas as noites no sétimo andar, o das goteiras. Sem identidade. Sem bagagem. Refugiando-se no escuro até virar um cavalo [...] entrava homem e virava um cavalo" (Telles, 1999, p. 73). Igualmente, o gato Rahul, com seus relatos que perpassam diferentes épocas e corpos: "Foi para fugir de mim mesmo que inventei os outros corpos, que me alimentei desses outros" (Telles, 1999, p. 59).

A importância da memória como partícipe ressalta-se no projeto de construção memorialista que almeja Rosa Ambrósio, anunciado, em sua simbologia de outro e de espelho, logo no início do romance: "Posso começar assim as minhas memórias: Quando nos olhávamos eu via minha beleza refletida nos seus olhos" (Telles, 1999, p. 10). Os registros memorialísticos utilizam-se de aspectos conscientes e inconscientes ligados ao universo mítico e social no qual estamos envolvidos. Implícito e explícito interagem em estruturas que, não sendo autônomas, ultrapassam uma condição meramente pessoal ou coletiva. São imagens inseridas em práticas e transformadas em palavras que, por sua vez, receberão novas interpretações a partir do ato de sua leitura pelo outro, um outro oriundo de um universo já diferenciado do autor, narrador ou personagem.

Se a infância, especialmente por suas normas rígidas de moral e de educação, possui uma quota de dor e desalento, é, de longe, o lugar comumente escolhido como refúgio: "Fomos felizes, hem, mamãe?, pergunto e estendo a mão para apertar a sua" (Telles, 1999, p. 17). Tempo e espaço onírico de origem, por ser em grande parte idealizado, a infância acolhe, acarinha, garante um consolo necessário e viabiliza a sobrevivência. É a casa ideal, protetora, nem sempre única, não importa onde a localizemos, desde que seja distanciada de um presente no qual o corpo se degrada. Um corpo frágil que contrapõe a finitude da existência humana a sonhos juvenis que retornam, não raro com ânsias redobradas, sempre inacessíveis (Bachelard, 2008; Fonseca, 2004; Goldenberg, 2013).

A intenção de escrever suas memórias, anunciada pela protagonista de Telles, une as três dimensões temporais: visando a uma escrita futura, é um repensar no presente que sinaliza como sendo capaz de propiciar sentido a vivências que Rosa Ambrósio anseia por recuperar. Porém, é algo mais amplo do que a simples coleta de memórias, encontramo-nos frente ao relato da vivência desse processo no momento em que ocorre, são relatos gravados na presença de Rahul, o enigmático gato da casa, com intromissões vigilantes e protetoras de Dionísia. Ou seja, mais do que a memória em si, acompanhamos a evocação e recordação vivenciadas pela personagem na velhice durante a coleta dessas memórias. Desse modo, enfatizam-se questões atinentes à identidade consolidada pela presença ou ausência da nomeação, o nome próprio como afirmação de si e encontro, ou perpétua procura, de origens.

A nomeação de Rosa Ambrósio impõe-se já no capítulo inicial. Sozinha no quarto, protegida do público externo ou mesmo familiar, a atriz recorda a manchete escandalosa da primeira página de um jornal de cunho sensacionalista: "A atriz Rosa Ambrósio é carregada para fora do avião completamente embriagada" (Telles, 1999, p. 9). Essa percepção negativa efetuada pela imprensa, externa, reflete a percepção igualmente negativa que Rosa Ambrósio faz de si, uma baixa autoestima carregada de rancor, mas também repleta de um autoengano e de uma noção de grandeza excessiva que divide o espaço com uma clara conscientização da decadência. Rosa Ambrósio, inclusive, usa a decadência como arma e a joga sobre o leitor em um desafio, como se dissesse: "olhe-me, é isso que eu sou. E estou viva".

A atriz, em todo o contexto da história, é dependente de Dionísia, de idade próxima à dela, ambas havendo passado pelo processo de menopausa na mesma época. Dionísia é desengonçada, feia, quase bruta, velha e resistente, é uma personagem supostamente secundária que, no entanto, acompanha toda a narrativa. Escudeira fiel, é quem sempre está por perto, não Diogo, o amante e o sonho, mas Dionísia, a cuidadora, a realidade crua, espelho dolorido e que, ao mesmo tempo, lhe dá apoio, traz o chá quente, absorve no próprio corpo, enrugado e com artrite, as dores que deveriam ser perceptíveis no corpo da patroa. É ela quem viabiliza a sobrevivência de Rosa Ambrósio, seus passos são pilares e elos com a vida real:

Os passos ficam mais próximos. Dionísia acendeu a luz. [...] Afasta-se num andar pesado, ela pisa como o Destino. Saiu da cena. [...] E a outra quer que me vista, me enfeite, mas por que enfeitar este corpo que agora detesto? Nem é detestação mas 
desprezo, o traidor. [...] Abro os olhos. Dionísia com seu casaco de tricô, gorro e meias de lã, está saindo. Ou chegando, nunca se sabe (Telles, 1999, p. 48-49).

Dionísia recebeu o nome de um deus ligado à vida eterna, às alegrias do vinho, do teatro e da dança, nome tão improvável como perfeito para evocar a passagem inexorável do tempo e o rigor do destino. É ela quem, com os pés firmemente postados no chão cotidiano, controla os dias e os santos no calendário cujas folhas vão sendo retiradas uma a uma. E é a velhice, configurada em Dionísia, o que dá apoio a Rosa Ambrósio. Acompanhando fielmente sua patroa, mostra-se sustento e mediação com o mundo externo. Porém, é necessário lembrar, ao mediar a crueza da percepção, também é ela quem reduz o contato direto com a realidade e recrudesce a dependência: "Quando ela começou a tirar minha roupa entreguei-me com a humildade de um manequim de vitrine. Suas mãos são ásperas mas quentes" (Telles, 1999, p. 116).

O fim da juventude representou para Rosa Ambrósio a saída do palco. As opções de papéis possíveis já dependem menos do talento e capacidade pessoal e mais do que existe disponível no mundo que a cerca, cada vez mais restrito. Há uma mudança aqui, uma perda de poder, o retorno à cena sujeita-se a uma ação externa, não própria. De protagonista, tornou-se personagem passiva, na vida e nos palcos.

Ao declarar que "só nos palcos, não é estranho? Sempre fui inteira" (Telles, 1999, p. 159), Rosa Ambrósio ressalta a importância desse espaço como constitutivo de sua existência, afirmando, inclusive, que suas fugas nunca ocorreram no teatro, que sempre se entregou inteira aos personagens que escolheu, suas fugas ocorreram na vida. "Representei então melhor do que vivi?" (Telles, 1999, p. 160), pergunta, uma indagação que cresce em impacto porque agora se percebe em um papel que não escolheu: ninguém escolhe envelhecer.

Essa questão perpassa o texto e é abordada por Lygia Fagundes Telles de um modo ao mesmo tempo sensível e cruel. Uma abordagem ambígua, porque a ambiguidade e a contradição fazem parte do tratamento recebido pelos idosos. E não apenas no momento atual, a convivência com a velhice tem uma longa história de diálogo entre extremos: por um lado, o medo da decadência e da morte; por outro, a exaltação frente à capacidade de sobreviver.

As horas nuas transita entre esses extremos, é um texto sobre fragilização e empoderamento. Suas personagens obrigam a um confronto direto, retiram máscaras protetoras e inviabilizam autoenganos ilusórios como os de que a velhice seria a decifração final, compensaria e daria sentido a todo o percurso anterior. No texto, envelhecer é uma continuidade incessante e caricaturizada da vida, "todo um mundo de coisas sumindo no sorvedouro" (Telles, 1999, p. 41), os anos a mais não nos tornam sábios ou moralmente exemplares, avisa a autora, apenas perdemos poderes e nos afundamos mais em nossas limitações.

Susan Sontag aborda o assunto destacando os efeitos que a visão do corpo envelhecido provoca especialmente sobre as mulheres. Seu texto "The double standart of aging", publicado no ano de $1972 \mathrm{e}$ ainda tristemente atual, avalia a sobrecarga representada por esse aspecto no momento em que a mulher, atingida a menopausa, abandona seu status de procriadora e, igualmente, reduz a possibilidade de manutenção de um ideário estético caracterizado pela valorização do rosto e do corpo jovens. Quando os instrumentos disponíveis não lhe permitem mais camuflar as alterações provocadas pela passagem dos anos, a mulher, fragmentada e objetificada, percebe-se incapaz de garantir a continuidade de seu papel no espaço identitário coletivo.

O retrato de uma atriz em seu declínio elaborado por Telles envolve mais do que o aspecto profissional da personagem, a cena descrita é a da exclusão, seja do palco, de um país, de um sistema político ou econômico ou de uma vida. Para o presente artigo, a leitura foi direcionada à gradativa retirada da vida pública e confinamento no espaço privado, por conta de um conjunto de estereótipos que embasam a percepção contemporânea da velhice. A busca de um refúgio privado e saída do universo exterior é sinalizada já na primeira página de As horas nuas:

Entro no quarto escuro, não acendo a luz, quero o escuro. Tropeço no macio, desabo em cima dessa coisa, ah! Meu Pai. A mania da Dionísia largar as trouxas de roupa suja no meio do caminho. Está bem, querida, roupa que eu sujei e que você vai lavar, reconheço, você trabalha muito, não existe devoção igual mas agora dá licença? Eu queria ficar assim 
quietinha com a minha garrafa, ô! delícia beber sem testemunhas, algodoada no chão feito o astronauta no espaço, a nave desligada, tudo desligado. Invisível (Telles, 1999, p. 9).

Rosa Ambrósio encontra-se em uma idade inicial de ingresso na velhice, ${ }^{2}$ mas a pressão que sofre por causa da sua faixa etária, pressão externa ou mesmo a oriunda de cobranças próprias, a torna representativa da velhice na década de 80 . Lido a partir desse enfoque, esse trecho inicial recria um ambiente desolador no qual se confundem cena, sentimento, ação e reação, ou falta de reação, conforme se observar.

Dos detalhes da cena, ressalta-se a trouxa de roupa suja sobre a qual ela desaba. É uma imagem que percorre o livro e exige um cuidado especial na leitura. É a roupa o que cobre o corpo para o trânsito social, mas, e isso é importante, apenas quando devidamente limpa, apenas após passar por um processo que pode ser concebido como de purificação. A referência a um processo purificador incide sobre todos os personagens, desde Rosa Ambrósio, com sua trouxa de roupa, sua clínica de desintoxicação, suas metamorfoses no palco, até Ananta, a jovem psicóloga, levada ao mundo do fantástico pelo homem que se transforma em animal, e Cordélia, a filha de Rosa, que ultrapassa sua juventude no contato sexual com homens mais velhos, de preferência excluídos socialmente.

Porém, de modo paradoxal, é a roupa suja o que impede o ferimento da queda, ameniza a mágoa que um contato direto com o chão poderia causar. Na cena criada por Lygia Fagundes Telles, é a trouxa de roupa suja o que abranda a queda de Rosa Ambrósio, transfigurando-se nos filtros que criamos ao longo da vida. Filtros complexos que, como as frases lidas e repetidas diariamente por Dionísia, são verdade mediada pelo autoengano, por papéis, religiões ou bebida: ao amenizarem o sofrimento, permitem-nos apenas o contato que acreditamos sermos capazes de suportar. A velhice, usada, gasta, mas ainda assim recanto de aconchego. Cruel, mas real em sua parcialidade.

A menção à sujeira e à dificuldade de limpeza aparece em outro momento, separando-se do universo privado e ampliando seu contexto para o coletivo, para os espaços públicos, a rua, o mar, as pessoas: "As pessoas chafurdam no lixo e parecem contentes, não sentem o lixo aqui fora, o lixo no particular, pisam nele e não se importam. Os homens da limpeza não dão mais conta ou entraram em greve, a greve é geral. A rua suja, o teatro sujo. A televisão" (Telles, 1999, p. 19).

A vida já corrompeu todos os espaços, físicos ou psicológicos, não há mais um sítio que possa ser chamado de lugar. Apenas o chão do quarto, cuja luz, tênue e nebulosa, pode confundi-lo com um espaço de memória. Rodeada de roupas sujas, usadas, Rosa Ambrósio não tem forças para camuflar suas verdades nos novos papéis sociais que lhe foram impingidos e se percebe verdadeira assim, com suas trouxas imundas, corrompidas, com suas manchas, seus cheiros, seu gosto à vinho velho.

Fora da área médica, obras de ficção ou pesquisas sobre a velhice são poucas antes da década de 80. No ano de 1979, Ecléa Bosi publicou Memória e sociedade: lembranças de velhos, ainda referência em estudos sobre o tema. Simone de Beauvoir, nove anos antes, em 1970, já escrevera A velhice, e Phillipe Ariès, em 1960, publicou História social da criança e da família. São estudos que traçam um perfil histórico da maneira como a diferenciação da figura do idoso foi se consolidando nos séculos XIX e XX e abrem caminhos para debate e investigação. Porém, podem ser considerados quase exceção em uma realidade editorial que dificilmente ultrapassava a dicotomia vilão-sábio ligada ao imaginário sobre o idoso desde a Antiguidade.

Nesse sentido, é interessante observar a figuração da velhice como nos chegou da mitologia grega, na qual se destacam três histórias: a de Geras, a da Sibila de Cumes e a de Tithonus. Sibila e Tithonus são humanos que receberam o dom da vida longa, mas sem receberem o da juventude igualmente longa. Suas histórias são trágicas e os anos a mais apresentam-se como um peso a ser carregado e não como recompensa divina.

\footnotetext{
${ }^{2}$ Rosa Ambrósio enquadra-se no que hoje chamamos de idoso jovem, ou seja, o período inicial da velhice, quando o idoso, mesmo estando aposentado e afastado da atividade profissional, é plenamente autônomo, envolve-se em projetos e realiza diferentes atividades sem ajuda ou acompanhamento constante. A personagem, percebida como "velha" no texto de Lygia Fagundes Telles, é exemplificativa da flutuação do conceito de velhice, da forma como nossas noções sobre o tema passaram por mudanças significativas no transcurso de poucas décadas.
} 
Já Geras representa mitologicamente a velhice e assume uma posição ambígua no Olimpo. É desprezado por personificar a decrepitude, considerado um deus cruel, porque apenas os outros deuses não são submetidos à fatalidade de seus desígnios. Não obstante, recebe o respeito de homens e deuses, sendo procurado como conselheiro sábio, possuidor de uma experiência só adquirível com a passagem dos anos.

Inimigo a ser temido ou sábio capaz de aconselhar em momentos difíceis, há uma dicotomia prejudicial visível. Porém, mais prejudicial e não igualmente visível é outro aspecto que tem caracterizado, de forma majoritária, o modo como lidamos com o idoso na sociedade contemporânea: a indiferença. Ecléa Bosi trabalha essa questão, alertando para como proteger, muitas vezes, termina se constituindo em sinônimo de desconsiderar, desrespeitar e subjugar:

A característica da relação do adulto com o velho é a falta de reciprocidade que pode se traduzir numa tolerância sem o calor da sinceridade. Não se discute com o velho, não se confrontam opiniões com as dele, negando-lhe a oportunidade de desenvolver o que só se permite aos amigos: a alteridade, a contradição, o afrontamento e mesmo o conflito (Bosi, 1994, p. 78).

Nas várias narrativas que se mesclam ao longo de As horas nuas, as vozes se cruzam, mas o diálogo não se concretiza. Fechados em seus mundos, as personagens permanecem em suspenso, sem vínculos concretos de pertencimento. O diálogo, quando ocorre, não raro é memória, real ou imaginária, delírios, criações da personagem, do narrador ou do autor, espaços e objetos que quando se misturam e relacionam não se encontram temporal ou geograficamente próximos. Cada elemento permanece preso em um círculo vicioso e solitário, marcado pelo silêncio ou por um jorrar de palavras que se extinguem no próprio excesso, incapazes de proporcionar compreensão e reduzidas a formas particulares de alheamento. Esse alheamento é registrado por Rosa Ambrósio, em uma amargura fortificada pela consciência:

Tudo somado, um longo plano de evasão fragmentado em fugas miúdas. Diárias. Que foram se multiplicando, não leio mais jornais, desliguei a TV com suas desgraças em primeiríssima mão, crimes humanos e desumanos, catástrofes e calamidades naturais e provocadas, ah!, um cansaço. Por que ficar sabendo tudo se não posso fazer nada? Posso dar água aos flagelados ressequidos? Dar uma toalha de rosto aos inundados? Hem?!... As tragédias se enredando sem trégua. Não tenho culpa se tomei horror pelo horror conformado (Telles, 1999, p. 10).

Um alheamento que se reforça também em seu desejo de enlouquecer: "Se enlouquecesse podia ser uma solução, não preciso morrer, apenas enlouqueço, não conheço mais ninguém, não conheço, esqueci. Uma louca limpa, sem o ranho escorrendo, sem a baba" (Telles, 1999, p. 43). Uma louca limpa, ressalva Rosa Ambrósio, pois seu anseio não desconhece a realidade por trás da imagem teatralizada: "O louco de verdade come merda mas no teatro ele pode ficar sublime" (Telles, 1999, p. 46). E, como o louco limpo, o velho comportado, porque a velhice, idealizada ou vilanizada, é obscena, uma "palavra desprezível", como declara, preferindo falar em "madureza. Idade da madureza" (Telles, 1999, p. 33): "A gente vai perdendo. Perdendo uma coisa atrás da outra, primeiro, a inocência, tanto fervor. A confiança e a segurança. Os dentes e a paciência, cabelos e casas, dedos e anéis, gentes e pentes [...] ô! meu Pai, tantas perdas" (Telles, 1999, p. 41).

É um processo de perdas que cresce em uma velocidade maior do que a que realmente vivenciamos no envelhecimento, ampliado por uma sobrecarga de estereótipos e preconceitos que não correspondem à realidade inerente à velhice humana. Medos concretados ao longo da existência conjugam-se com hábitos prejudiciais e reforçam pressões que é preciso modificar para garantir uma real qualidade de vida. Sibila Marques analisa o tema e utiliza o termo "idadismo" 3 para referir "atitudes e práticas negativas generalizadas em relação aos indivíduos baseadas somente numa característica - a sua idade" (Marques, 2011, p. 18). Ainda que o termo

\footnotetext{
${ }^{3}$ A expressão aparece pela primeira vez no artigo “Age-Ism: another form of bigotry”, publicado pelo psicólogo norteamericano Robert Burtler no ano de 1969. Burtler utiliza o termo Age-ism para descrever as reações negativas de um coletivo do subúrbio de Maryland, Estados Unidos, frente à implantação de empreendimento imobiliário direcionado a idosos. Posteriormente, o autor adota a forma ageism, que se mantém nos estudos atuais sobre o tema. A expressão foi traduzida para o português como "idadismo", forma utilizada por Sibila Marques.
} 
não se refira apenas aos idosos, mas a ações baseadas em critérios etários nas mais diferentes faixas etárias, é na velhice que os aspectos negativos são mais evidentes.

As origens do idadismo não se encontram em uma única causa, sendo resultado de um encadeamento complexo que envolve, entre outros, aspectos culturais, sociais e econômicos. Entretanto, dentre uma multiplicidade de fatores, Marques destaca três: "o processo de categorização por idades, a inactividade das pessoas idosas e a percepção da ameaça dos gastos com o envelhecimento, e o predomínio da cultura da juventude" (Marques, 2011, p. 36).

Neste ponto, é interessante notar que a questão não é apenas como os idosos são vistos, é um quadro que se relaciona intimamente com o modo como a sociedade contemporânea vê e valoriza o papel exercido pelo jovem no interior da família e da comunidade. Norbert Elias (2001) atenta para o isolamento verificado na nossa sociedade com relação ao que nos lembra da proximidade da morte, no que se inclui de forma contundente a velhice. A visão da dor e da morte foi retirada do ambiente familiar e comunitário e confinada em espaços distanciados do olhar público, como hospitais e instituições de assistência, onde as visitas são regradas e seguem rituais que se destinam mais ao ocultamento e dispersão sensória do que ao apoio na realização do luto e superação do sofrimento (Elias, 2001; Rodrigues, 2006).

Segundo Elias (2001), a ocultação da morte constituiu-se conjuntamente com a valorização extrema da juventude. O que se observa é uma fragmentação da vida, não um olhar que abranja e integre o todo que é o homem, mas o condicionamento das diferentes etapas em categorias que passam a ser estudadas, compreendidas e vividas como momentos não interligados entre si.

Quando falamos do ciclo da vida humana, o modelo mais utilizado pelo senso comum é ainda o da tripartição entre infância, idade adulta e velhice, correlacionando esses conceitos diretamente com outra tripartição, altamente perniciosa, entre aprendizado, auge e decadência. Parte-se da ideia de um ser humano que se constrói, usufrui dessa completude com o que chamamos de "produtividade" e, depois, excluído do sistema de produção, entrega-se a uma espera monótona da morte do corpo, o espírito sem meios ou força para se expressar.

Pesquisas recentes, entre as quais sublinhamos os trabalhos desenvolvidos por Debert (1999), Fonseca (2004) e Goldenberg (2013), já rejeitam essa tripartição, refutando a noção de que a identidade possa ser "concluída". Pelo contrário, o processo de construção identitária definese hoje pelo movimento, somos seres perpetuamente inacabados. E somos também heterogêneos, etária, social e individualmente, como enfatiza António Fonseca:

Com efeito, à medida que as pessoas envelhecem, os seus percursos de vida vão-se diferenciando cada vez mais uns dos outros, quer devido ao cruzamento de variáveis de ordem biológica e cultural quer devido à influência exercida por toda uma série de acontecimentos de vida que vai marcando os seus comportamentos e as suas personalidades (Fonseca, 2004, p. 20).

A cada dia, novos papéis são aprendidos e assimilados. Quase três décadas após a publicação de As horas nuas, é tempo de questionar que papéis são esses. Como esses anos de visibilidade da velhice mudaram nossas formas de vivenciar o envelhecimento?

A tendência atual é de uma visão mais positiva e confiante, como uma época em que o indivíduo, tendo consolidado uma estrutura básica em termos financeiros, familiares e afetivos, permite-se a abertura para novos projetos. A ideia corrente, afirma Fonseca (2004, p. 14), é de que "As experiências vividas e os saberes acumulados são ganhos que oferecem oportunidades de realizar projetos abandonados em outras etapas e estabelecer relações mais profícuas com o mundo dos mais jovens e dos mais velhos". Contudo, o autor alerta que essa visão positiva abrange apenas o momento mais inicial da velhice, constatando-se uma espécie de negação das consequências de uma longevidade mais avançada. Um enfoque dos estudos voltado mais para o período de atividade e autonomia pode resultar em uma ilusão de eterno rejuvenescer, um mero adiamento do confronto do indivíduo com a sua finitude. Na mesma linha, Debert afirma:

[...] o sucesso surpreendente dessas iniciativas [grupos de terceira idade, escolas abertas, turismo direcionado, entre outras] é proporcional à precariedade dos mecanismos de que dispomos para lidar com a velhice avançada. A nova imagem do 
idoso não oferece instrumentos capazes de enfrentar a decadência de habilidades cognitivas e controles físicos e emocionais que são fundamentais, na nossa sociedade, para que um indivíduo seja reconhecido como um ser autônomo, capaz de um exercício pleno dos direitos de cidadania (Debert, 1999, p. 15).

No ano de 2013, a antropóloga brasileira Miriam Goldenberg publicou A bela velhice. Apoiada em informações coletadas por meio de um sistema de entrevistas que envolveu indivíduos de diferentes grupos etários e classes econômicas, Goldenberg propôs-se a analisar os significados da velhice e do envelhecer no contexto de uma sociedade como a brasileira, marcada por um imaginário de consumo e valorização não raro extrema da juventude e do corpo feminino jovem.

A bela velhice debate diferenças entre homens e mulheres idosos e a singularidade dessa geração que ora se aposenta, tendo em vista ter convivido com mudanças socioculturais marcantes e que nem sempre viabilizaram períodos efetivos de transição e adaptação. Entre essas mudanças, ressaltam-se as que se referem ao contexto do imaginário e aos papéis desempenhados no cotidiano público ou privado.

Para Goldenberg, homens e mulheres distanciam-se não raro de forma conflitante no período. O envelhecimento é citado pelas entrevistadas como assustador, refletindo toda uma cultura de valorização do corpo jovem, especialmente no caso feminino, e de visão do corpo do idoso como degradado, feio, descartável. Desse modo, o ingresso na velhice mostra-se mais dolorido para o elemento feminino, o que se altera de modo gradativo com uma vivência posterior da velhice de forma mais intensa e libertadora por parte das mulheres. Ao saírem do espaço público, a tendência verificada por Goldenberg é de uma busca de afetividade familiar por parte dos homens, provocando uma dependência e uma reclusão maior no ambiente caseiro; já as mulheres, segundo a pesquisadora, percebem-se libertas de obrigações familiares e sociais, assumindo um caráter mais centrado em projetos próprios, voltados ao usufruto de uma liberdade social até então por elas pouco conhecida. ${ }^{4}$

Não obstante as mudanças já verificadas, há um caminho imenso que ainda é necessário percorrer. A leitura de obras posteriores à de Lygia Fagundes Telles delineia medos e preconceitos que mesmo hoje integram nosso dia a dia, clara ou furtivamente. A imagem midiática da velhice "ativa", consubstanciada na ironia da expressão "melhor idade", mantém a juventude como modelo idealizado. Manter-se jovem, manter uma mente jovem, torna-se frase de uso corrente em peças publicitárias, livros de autoajuda e inclusive em trabalhos mais aprofundados do tema. A velhice real retorna, assim, ainda que em uma idade posterior, à invisibilidade.

A dor de Rosa Ambrósio, necessária em sua voracidade, cresce em importância quando lida como crítica e ruptura. É enfrentamento a um universo social no qual a beleza é jovem e a velhice um tabu marcado pelo medo, não raro mesmo pela repulsa, não há espaço para o ameno quando é nosso o corpo que envelhece. Tão difícil quanto desafiar o preconceito e a aversão do outro é a ação de aceitar que a imagem refletida não é exterior. A idealização do corpo jovem precisa ser desconstruída para que esse outro, o velho que se mostra no espelho, possa assumir sua forma.

A visão negativa da velhice, embora fortemente interiorizada, já se comprovou como equívoco e tem sido substituída pela averiguação sobre o que, nesse período, é inevitável, o que decorre de opções pessoais ou coletivas e o que decorre de estereótipos que há muito deveriam ter sido ultrapassados. É uma mudança gradativa de viés, resultante também do número crescente de pesquisas na área, que envolvem diferentes setores, métodos e linhas de pensamento, enfatizando a variedade e inconclusividade de definições sobre o tema.

Estamos em um momento distinto: a juventude não deve ser vista como modelo a ser eternamente perseguido, a velhice deve se observar como o próprio modelo. $\mathrm{O}$ objetivo não deve ser o idoso parecer jovem, manter o corpo formatado em moldes típicos da juventude,

\footnotetext{
${ }^{4}$ É importante ressalvar a geração de idosos pesquisada por Goldenberg, na qual se incluem as personagens de Lygia Fagundes Telles. Novas vivências familiares e a mentalidade diferenciada com que os jovens hoje lidam com aspectos relativos ao ambiente público e privado implicarão também alterações quando do ingresso na velhice por esses jovens.
} 
mas, sim, parecer idoso com a amplidão e diversidade que esse parecer idoso representa. Nesse sentido, o texto de Telles carrega-se de frases de alerta, reivindicando um novo olhar, aprofundado e mais consciente. Como a do primo advogado ao perceber o quanto se manteve alheio à realidade da história: "Mas não era mesmo incrível? Não ter visto o canteiro das pequenas mascaradas que sempre estiveram ali. O que mais teria deixado escapar?" (Telles, 1999, p. 246). Ou, em outro momento, na voz da própria Rosa Ambrósio: "Ele me conhece e não me conhece, as conclusões são apressadas demais" (Telles, 1999, p. 173).

Precisamos ter essa mescla de sensibilidade e racionalidade no repensar de nossas posições sobre a velhice. Se nos permitirmos ver e investigar, há muito a descobrir, realidades que ultrapassam estereótipos construídos a partir do medo e da nossa incapacidade de enfrentamento. Mudar o estigma pejorativo assumido pela palavra é permitir, como Rosa Ambrósio, que trouxas de roupas sujas sejam troféus em trajetórias plenas de retomadas, continuidades e recomeços.

\section{Referências}

ARIÈS, Phillipe (2006). História social da criança e da família. Tradução de Dora Flaksman. Lisboa: LTC.

BACHELARD, Gaston (2008). A poética do espaço. Tradução de Antonio de Pádua Danesi. São Paulo: Martins Fontes.

BEAUVOIR, Simone de (1990). A velhice. Tradução de Maria Helena Franco Monteiro. Rio de Janeiro: Nova Fronteira.

BOSI, Ecléa (1994). Memória e sociedade: lembranças dos velhos. São Paulo: Companhia das Letras.

BURTLER, Robert (1969). Age-Ism: another form of bigotry. The Gerontologist, Oxford, v. 9, n. 4, p. 243-246. Disponível em: https://academic.oup.com/gerontologist/article-abstract/9/4_Part_1/243/569551. Acesso em: 10 fev. 2018.

CARVALHO, Alfredo L. C. (2016). A fascinante ficção de Lygia Fagundes Telles: seis estudos críticos. São Paulo: Vitrine Literária.

DEBERT, Guita (1999). A reinvenção da velhice: socialização e processos de reprivatização do envelhecimento. São Paulo: Fapesp.

ELIAS, Norbert (2001). A solidão dos moribundos seguido de "Envelhecer e morrer". Tradução de Plínio Dentzien. Rio de Janeiro: Zahar Editores.

FONSECA, António Manuel (Coord.) (2004). Desenvolvimento humano e envelhecimento. Lisboa: Climepsi.

GOLDENBERG, Miriam (2013). A bela velhice. São Paulo: Record.

MARQUES, Sibila (2011). Discriminação da Terceira Idade. Lisboa: FFMS.

PEIXOTO, Clarice (1998). Entre o estigma e a compaixão e os termos classificatórios: velho, velhote, idosos, terceira idade. In: BARROS, Myriam Moraes Lins de (Org.). Velhice ou terceira idade? Rio de Janeiro: FGV. p. 69-84.

RODRIGUES, José Carlos (2006). Tabu da morte. Rio de Janeiro: Fiocruz.

SONTAG, Susan (1972). The double standard of aging. The Saturday Review, New York, p. 29-38, 23 Sep.

TELLES, Lygia Fagundes (1998). Seminário dos ratos. Rio de Janeiro: Rocco.

TELLES, Lygia Fagundes (1999). As horas nuas. Rio de Janeiro: Rocco.

TELLES, Lygia Fagundes (2009). A noite escura e mais eu. São Paulo: Companhia das Letras. 